$\infty$

0

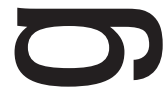

-

ת

1

$\longrightarrow$ 



\title{
VULNERABILIDADE E RISCO À CONTAMINAÇÃO DOS SOLOS DA ÁREA DE RECARGA DO AQUÍFERO GUARANI NO ESTADO DE GOIÁS
}

\author{
NATURAL VULNERABILITY AND RISK OF SOILS IN THE AREAS OF THE GUARANI AQUIFER'S RECHARGE IN \\ THE STATE OF GOIÁS, BRAZIL
}
VULNÉRABILITÉE ET RISQUE À LA CONTAMINATION DES SOLS DANS LA ZONE DE RECHARGE DE L'AQUIFÈRE LE GUARANI À L'ETAT DE GOIÀS, BRÉSIL

\author{
Thaís Moreira Alves - Universidade Federal de Goiás (IESA/UFG) \\ thais.moreiraa@gmail.com
}

\author{
Selma Simões de Castro - Universidade Federal de Goiás (IESA/UFG) \\ selma@iesa.ufg.br
}

\section{Resumo}

Este trabalho tem como objetivo apresentar a estimativa da vulnerabilidade natural e risco dos solos à contaminação nas áreas de recarga do Aqüífero Guarani, no sudoeste do Estado de Goiás (SAG/GOIÁS). Para estabelecer as classes de vulnerabilidade desses solos utilizou-se de técnicas de SIG, cruzando-se os mapas de declividade dos terrenos com o de solos, o de condutividade hidráulica e o de uso do solo, todos na mesma escala, obtendo-se as classes de vulnerabilidade e de risco. Avaliou-se que $45 \%$ das áreas de recarga do aqǘfero possuem vulnerabilidade muito alta e $47 \%$ são consideradas da classe alta, juntas somando mais de $90 \%$ da área total de recarga do aqǘfero no Estado de Goiás. Calculou-se que 32,8\% apresentam alto risco e 27,5\% apresentam muito alto risco somado $60 \%$ do total da área. Concluiu-se que a vulnerabilidade e risco da área de recarga do SAG em Goiás são elevados e por isso inspiram cuidados, sobretudo preventivos, com o uso, manejo e conservação dos solos.

Palavras-chave: Aqüífero Guarani. Vulnerabilidade. Risco de contaminação.

\begin{abstract}
This paper aims to present the estimate of the natural vulnerability and risk of soils, in the areas of the Guarani aquifer's recharge, in the State of Goiás (SAG/GOIÁS). To establish the classes of vulnerability of these soils, the lands map of declivity was crossed with the hydraulic conductivity one, and the following classes were obtained: low, moderate, high and very high. It was evaluated that $45 \%$ of the recharge areas has very high vulnerability, and $47 \%$ are considered high class, togheter these areas represent more than $90 \%$ of the total area of occurrence of the Guarani aquifer in the State of Goiás which inspires specific care in regards of use and handling of the lands. $32,8 \%$ of the recharge areas has high risk and $27,5 \%$ has very high risk, $60 \%$ of the total of the area.
\end{abstract}

Key-words: Guarani Aquifer. Vulnerability. Risk of contamination.

\section{Résumé}

L'objectif de ce travail c'est d'estimer la vulnerabilitée et le risque des sols à la contamination dans la zone de recharge du systeme Aquifère Guarani (SAG/ GOIÁS), placé dans le Sud Ouest de l'état de Goiás, Brésil. Pour estimer et aussi d'évaluer le degré de vulnérabilitée et les risques des sols, ont été utilizés techniques de SGI, superposant les cartes de déclivité, des sols, de la conductivitée hydraulique et de l'utilization des sols, à la même échélle. Les classes obtennues montrent que un peu plus de $45 \%$ présentant une vulnerabilité trés haute et presque $47 \%$ une vulnérabilité haute, les deux sommant plus de $90 \%$ de la zone de recharge de l'aquifère dans l'état de Goiás. Concernant le risques ont peut

\begin{tabular}{|l|c|c|c|c|c|c|}
\hline Boletim Goiano de Geografia & Goiânia - Goiás - Brasil & v. 29 & n. 1 & p. 135-150 & jan. / jun. & 2009 \\
\hline
\end{tabular}


évaluer que $32,8 \%$ de la zone a été classée comme de haute risque et $27,5 \%$ come de trés haute, les deux sommant $60 \%$. Alos, la vulnerabilité et le risque à la contamination sont trés dangereux pour la zone de récharge du SG-Goiás et demandent des actions préventives dans la gestion de l'environment aindi que pour l'itinéraire techinque et conservation des sols.

Mots-clefs: Système Aquifère Guarani (SAG). Vulnérabilité. Risque de contamination.

\section{Introdução}

No século XX a demanda por água aumentou em mais de seis vezes, superando em duas vezes o crescimento populacional no período (BERBERT, 2003). O aumento do consumo deste recurso está relacionado com o padrão de desenvolvimento adotado por nossa sociedade, pautado no conforto da vida urbana moderna, no crescimento acelerado da população e na aglomeração de pessoas em centros urbanos (ALMEIDA, 2003).

Sabe-se que aproximadamente $69 \%$ da água doce do mundo não estão disponíveis para o consumo (LIMA, 2008), e que a maior porção de água doce disponível, quase 30\%, encontra-se nos lençóis subterrâneos cujo consumo vem aumentando rapidamente. No caso do Brasil, em particular, os recursos hídricos subterrâneos contribuem com 51\% da demanda para o abastecimento humano, permitindo o atendimento de comunidades pobres ou distantes das redes de abastecimento público (GOIÁS, 2006; ANA, 2008).

Os aqüíferos, de modo geral, possuem água pura, logo sem poluentes ou contaminantes, podendo assim ser utilizados diretamente para o consumo, por estarem mais profundos e, em princípio, mais protegidos. Além de não necessitarem de grande tratamento para o uso da população, os custos de captação e distribuição são mais baixos se comparados às águas superficiais que em geral demandam a construção de reservatórios. No entanto, se contaminados, torna-se difícil sua descontaminação, uma vez que técnica e economicamente torna-se praticamente inviável sua recuperação devido, sobretudo, à sua profundidade (BERBERT, 2003).

Dentre os sistemas aqüíferos brasileiros destaca-se o Sistema Aqüífero Guarani (SAG), por possuir uma notável importância social e econômica, sendo um dos maiores reservatórios mundiais de água subterrânea e representar uma grande reserva estratégica para o Cone Sul, já que ele tem potencial para abastecer toda a população brasileira por cerca de 2.500 anos, de acordo com a Embrapa (2008). 
Considerando a importância das pesquisas que visam estabelecer os níveis de proteção desses reservatórios naturais e ressaltando a importância desse recurso como um importante reservatório de água doce de fácil acesso, este trabalho foca as áreas de recarga do SAG, abrangendo os municípios de Mineiros, Jataí, Santa Rita do Araguaia e Serranópolis, na microrregião do sudoeste goiano, Estado de Goiás.

O SAG vem sendo alvo de inúmeras pesquisas no Brasil e países vizinhos, em conseqüência de sua importância para a América do Sul e para o Brasil, em particular. Contudo, no Estado de Goiás, ainda são poucos os estudos a seu respeito, sendo que ele se encontra restrito à microrregião sudoeste goiano.

O trabalho objetiva estabelecer a vulnerabilidade e os riscos em que se encontram os solos da área de recarga do SAG nessa região, em termos de contribuir com subsídios para a avaliação do seu potencial de contaminação, pois o sudoeste goiano representa uma importante área agrícola brasileira, onde se usa intensamente defensivos, corretivos e fertilizantes agrícolas, contemplados agrupadamente neste trabalho.

Para estimar a vulnerabilidade à contaminação do SAG trabalhou-se com as relações entre os aspectos físicos da paisagem e o tipo de uso atual do solo. A espacialização da vulnerabilidade e de risco à poluição das águas do SAG se deu em forma de mapas obtidos através do uso de SIG, visando um melhor entendimento de sua variação espacial.

\section{Localização da área de estudo}

A área de estudo está localizada no sudoeste do Estado de Goiás (Figura 1), abrangendo os municípios de Jataí, Mineiros, Santa Rita do Araguaia e Serranópolis, situada na porção oeste da bacia sedimentar do Paraná. Essa região é considerada pela EMBRAPA como uma das cinco áreas críticas distribuídas ao longo das áreas de recarga do Aqüífero Guarani (EMBRAPA, 2008).

A Precipitação Média Anual na região é de $1.863 \mathrm{~mm}$ e a temperatura anual varia de $18^{\circ}$ a $20^{\circ} \mathrm{C}$. As culturas dominantes na área são: soja, sorgo, milho e cana-de-açúcar.

As vertentes da área de ocorrência do SAG variam de zero a seis graus de declividade, indicando predomínio de relevo suave, constituindo rampas longas, sem grandes quebras de gradiente. Localmente cerca de 10\% do total da área apresentam declividade superior a 12\%, (Tabela 1), as quais corres- 
pondem às bordas e escarpamentos suavisados das chapadas, denominação das formas aplainadas tabulares ou cuestifomes existentes na área. Trata-se, portanto, na maioria de área favorável à recarga de aqüíferos, do ponto de vista da topografia.

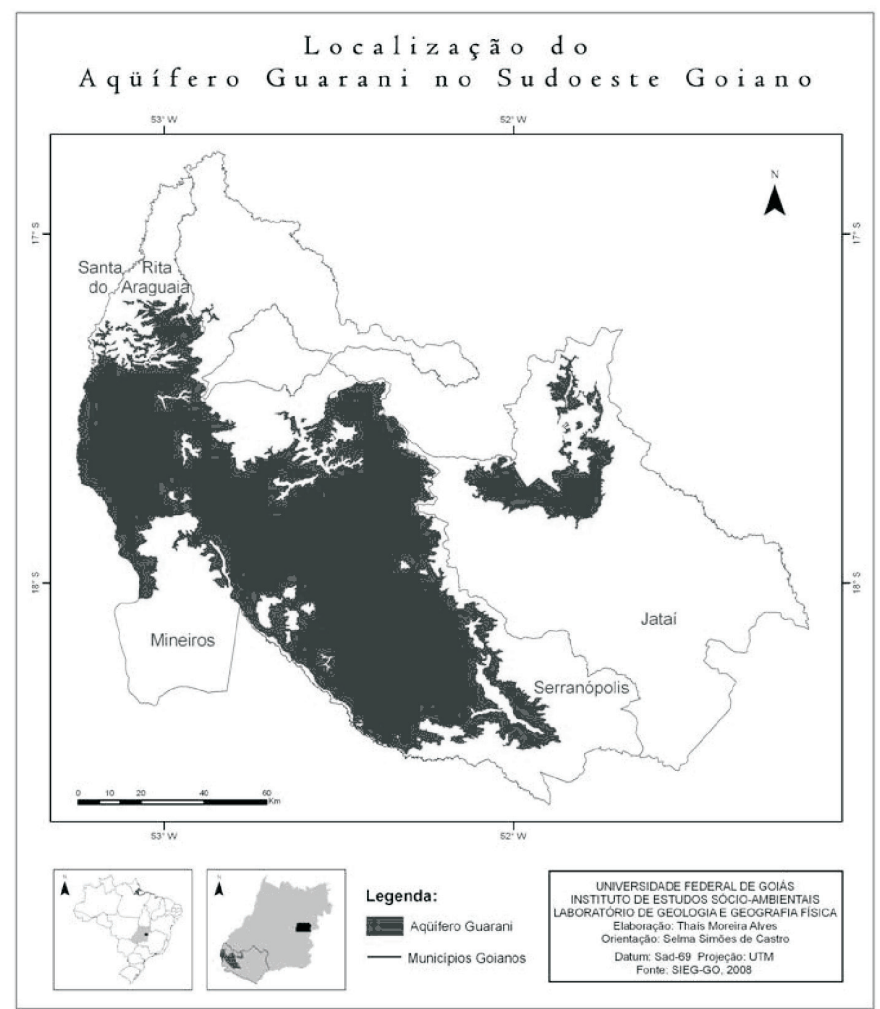

Figura 1 - Mapa de localização da área de estudo.

Tabela 1 - Classes de declive da área e suas devidas porcentagens

\begin{tabular}{lll}
\hline CLASSES DE DECLIVIDADE & ÁREA $\left(\mathbf{K M}^{2}\right)$ & ÁREA (\%) \\
\hline $0-6$ - baixa & $6.897,41$ & 75,03 \\
6 -12 - suave & $1.344,68$ & 14,63 \\
12 -18 - moderada & 672,27 & 7,32 \\
18 - 45 - acentuada & 278,34 & 3,02 \\
TOTAL & $\mathbf{9 . 1 9 2 , 7 5}$ & $\mathbf{1 0 0 , 0 0}$ \\
\hline
\end{tabular}

Fonte: SRTM/NASA (2008), organizado por ALVES (2008). 
Geologicamente, dominam os arenitos finos e quartzosos da Formação Botucatu, da Bacia Sedimentar do Paraná que dão origem aos solos igualmente arenosos finos, os Neossolos Quartzarênicos órticos, que passam lateralmente ao Neossolos Quartzarênicos hidromórficos, próximo aos fundos de vale. Nos topos regionais associados aos divisores ocorrem ainda solos de textura média a argilosa, classificados como Latossolos Vermelho-Amarelos e Latossolos Vermelhos, respectivamente, desenvolvidos sobre sedimentos terço-quaternários inconsolidados. Nas bordas e escarpas desses divisores ocorrem localmente os Neossolos Litólicos e afloramentos de rochas. Tais litologias e solos são reconhecidamente favoráveis à infiltração das águas pluviais, na condição de declive suave como assinalado.

\section{Metodologia}

Procedeu-se inicialmente à pesquisa bibliográfica e ao levantamento e compilação de documentos cartográficos existentes, em diversas escalas, os quais foram padronizados em uma mesma escala, 1:250.000, para fins de localização e delimitação da área de interesse, bem como de caracterização do seu meio físico, biótico e do uso e ocupação.

Quadro 1 - Classes de Condutividade Hidráulica dos Solos

\begin{tabular}{|c|c|c|}
\hline $\begin{array}{l}\text { Classes de Condutividade } \\
\text { Hidráulica (kv) }\end{array}$ & Valores em $\mathrm{Kv}$ em $\mathrm{m}^{3} \mathrm{~s}$ & $\begin{array}{l}\text { Classes ou Associações } \\
\text { de Classes de Solo }\end{array}$ \\
\hline Muito Alta & $>10^{-3}$ & $\begin{array}{l}\text { Neossolos Quartzarêni- } \\
\text { cos }\end{array}$ \\
\hline Alta & $10^{-3}$ a $10^{-5}$ & Latossolos \\
\hline Moderada & $10^{-6}$ & Argissolos, Nitossolos \\
\hline Baixa & $10^{-7}$ a $10^{-8}$ & $\begin{array}{l}\text { Cambissolos, Plintosso- } \\
\text { los, Neossolos Litólicos, } \\
\text { Gleissolos. }\end{array}$ \\
\hline
\end{tabular}

Fonte: Barbalho (2008), adaptado de Gomes et al., 1996.

Para elaboração dos mapas de vulnerabilidade, de risco e de condutividade hidráulica, utilizou-se a metodologia apresentada por Gomes, Spadotto e Pessoa (2002), que propuseram um método de avaliação de vulnerabilidade natural dos solos, como forma de subsidiar estudos relativos à movimentação de agroquímicos, principalmente àqueles volta- 
dos à avaliação de riscos de contaminação das águas subterrâneas. Tal metodologia foi aplicada também para o Estado de Goiás por Barbalho \& Campos (2008).

Para elaboração desses produtos, foi essencial o uso dos parâmetros de: declividade, classes de solos e condutividade hidráulica. A classificação da condutividade hidráulica dos solos foi gerada a partir do cruzamento dos dados de condutividade hidráulica das classes de solos com o mapa de solos. As classes adotadas são apresentadas no Quadro 1.

Com base nas curvas de nível extraídas da imagem do Shutlle Radar Topographic Mission - SRTM/NASA e dos pontos cotados, foi gerado o mapa de declividade no aplicativo SPRING 4.2., a partir da geração de uma grade triangular (TIN) e posteriormente do seu fatiamento. As fatias corresponderam às classes de declividades que foram definidas nos seguintes intervalos: baixa de 0-6\% (correspondem às áreas planas ou quase planas), suave de 6-12\% (áreas com relevo ondulado), moderada de 12-18\% (áreas inclinadas) e acentuado 18-45\% (vertentes fortemente inclinadas).

Com os dados de condutividade hidráulica e declividade foi estabelecida a relação matricial que resultou na classificação dos potenciais de infiltração e escoamento superficial da água no solo. Posteriormente, foi realizada a classificação da vulnerabilidade em função da integração das informações de condutividade hidráulica, declividade do terreno, potenciais de infiltração e de escoamento superficial da água (Tabela 2 e 3), com uso da ferramenta LEGAL do programa SPRING. As classes de vulnerabilidade estabelecidas foram as seguintes: muito alta, alta, moderada e baixa.

Tabela 2 - Potencial de infiltração em relação à declividade e condutividade hidráulica.

\begin{tabular}{l|llll}
\hline \multirow{2}{*}{$\begin{array}{l}\text { Condutividade } \\
\text { hidráulica }\end{array}$} & \multicolumn{3}{|l}{ Declividade (\%) } \\
\cline { 2 - 5 } & Baixa & Suave & Moderada & Alta \\
& $0-6$ & $6-12$ & $12-18$ & $18-45$ \\
\hline Baixa & Médio & Baixo & Baixo & Baixo \\
Média & Alto & Médio & Baixo & Baixo \\
Alta & Alto & Alto & Médio & Baixo \\
Muito Alta & Alto & Alto & Alto & Médio \\
\hline
\end{tabular}

Fonte: Barbalho (2008), adaptado de Gomes et al., 1996.

O potencial de infiltração classificado como alto e muito alto (em decorrência da elevada condutividade hidráulica e da baixa declividade) é 
indicador de alta vulnerabilidade à contaminação dos recursos hídricos subterrâneos. Já o potencial de escoamento classificado como alto, por sua vez, indica que a área é mais vulnerável à erosão e à contaminação dos recursos hídricos superficiais (BARBALHO \& CAMPOS, 2008).

Tabela 3 - Potencial de escoamento superficial em relação à declividade e a condutividade hidráulica.

\begin{tabular}{l|llll}
\hline \multirow{2}{*}{$\begin{array}{l}\text { Condutividade } \\
\text { hidráulica }\end{array}$} & \multicolumn{4}{l}{ Declividade (\%) } \\
\cline { 2 - 5 } & Baixa & Suave & Moderada & Alta \\
& $0-6$ & $6-12$ & $12-18$ & $18-45$ \\
\hline Baixa & Médio & Baixo & Baixo & Baixo \\
Média & Alto & Médio & Baixo & Baixo \\
Alta & Alto & Alto & Médio & Baixo \\
Muito Alta & Alto & Alto & Alto & Médio \\
\hline
\end{tabular}

Fonte: Barbalho (2008), adaptado de Gomes et al., 1996.

Por fim, a partir da integração dos dados de vulnerabilidade e de uso e ocupação das terras foi gerado o mapa de risco à contaminação, também utilizando a ferramenta LEGAL do aplicativo SPRING. As classes estabelecidas foram: baixo, moderado, alto e muito elevado.

\section{Vulnerabilidade e risco à contaminação do SAG}

A classificação da condutividade hidráulica dos solos, dos potenciais de infiltração e do escoamento superficial da água no solo, foram estabelecidos de modo a mapear a vulnerabilidade e o risco à contaminação do SAG em Goiás.

Como a maior parte dos declives da área de estudo são suaves e aproximadamente $83,8 \%$ dos solos apresentam condutividade hidráulica de alta a muito alta (Figura 2), representados, sobretudo, por Latossolos e Neossolos, pode-se concluir que a área possui condições favoráveis à infiltração e à percolação das águas, favorecendo então à recarga dessa, conforme também pode ser observado na tabela de condutividade hidráulica dos solos (Tabela 4). Esses altos valores de recarga do SAG tendem a diminuir à medida em que a formação se aprofunda e adquire condições de confinamento, subjacente aos basaltos da Formação Serra Geral. 
Figura 2 - Mapa de condutividade hidráulica dos solos do SAG no sudoeste goiano.

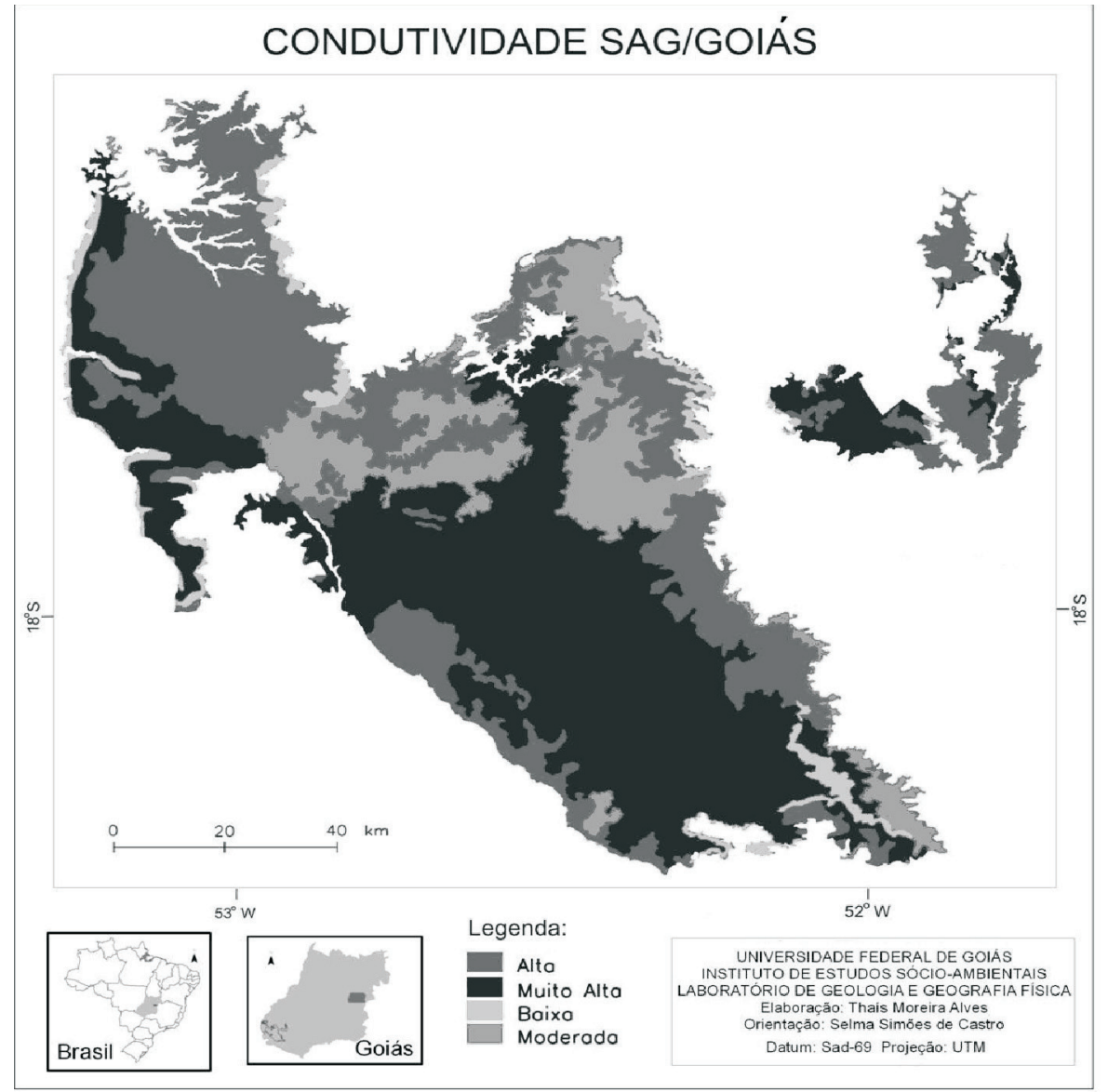

Tabela 4 - Distribuição das classes de condutividade hidráulica dos solos

\begin{tabular}{lll}
\hline & \multicolumn{1}{l}{ ÁREA } \\
\cline { 2 - 3 } CLASSES DE CONDUTIVIDADE HIDRÁULICA DOS SOLOS & $\mathbf{( k m}^{\mathbf{2}}$ & $\mathbf{( \% )}$ \\
\hline Alta & $3.384,9516$ & 36,82 \\
Muito Alta & $4.107,9996$ & 44,68 \\
Moderada & $1.308,5868$ & 14,25 \\
Baixa & 391,2148 & 4,25 \\
TOTAL & $\mathbf{9 . 1 9 2 , 7 5}$ & $\mathbf{1 0 0}$ \\
\hline
\end{tabular}


Foram identificadas quatro classes de vulnerabilidade à contaminação do SAG: muito alta, alta, moderada e baixa.

A Tabela 5 permite constatar que 45,6\% e 46,9\% das terras do SAG apresentam muito alta e alta vulnerabilidade à contaminação dos solos, respectivamnete, somando mais de $90 \%$ da área total. Consequentemente os recursos hídricos subterrâneos estão sujeitos a contaminação devido essa elevada vulnerabilidade dos solos.

Tabela 5 - Área das classes de vulnerabilidade a contaminação.

\begin{tabular}{lll}
\hline CLASSES DE VULNERABILIDADE & \multicolumn{1}{l}{ ÁA } & \\
\cline { 2 - 3 } & $\left(\mathbf{K m}^{2}\right)$ & $(\%)$ \\
\hline Baixa & 371,9440 & 4,05 \\
Moderada & 315,9172 & 3,44 \\
Mlta & $4.314,9348$ & 46,94 \\
Muito alta & $4.189,9716$ & 45,57 \\
TOTAL & $9.192,75$ & 100 \\
\hline
\end{tabular}

Apenas 4,05\% e 3,4\% da área correspondem a baixa e moderada vulnerabilidade, respectivamente, as quais se associam a relevos com declives acentuados ou moderados, com solos menos vulneráveis, de $\mathrm{Kv}$ moderada.

A área classificada como vulnerabilidade muito alta à contaminação localiza-se justamente nas áreas de recarga do Aqüífero Guarani as quais se encontram cobertas por Neossolos Quartzarênicos, em particular nos municípios de Mineiros e Serranópolis, como mostra a Figura 3. Nessas áreas, atividades com potencial de contaminação devem ser evitadas ou criteriosamente planejadas.

Esses dados confirmam a fragilidade que as áreas de recarga do SAG apresentam e deixam claro que cuidados específicos com o uso dos solos na região são essenciais. Os municípios de Serranópolis e Mineiros devem ser priorizados pois além de serem os que apresentam maior vulnerabilidade, são também os que apresentam a maior área representativa do SAG, e são utilizados com agricultura e pastagem. Essa situação se repete numa faixa à oeste do município de Santa Rita do Araguaia, justamente onde o uso do solo, é de predomínio agrícola.

Em 2003, conforme mostrava o mapa de vegetação e uso do solo (GEOGOIÁS, 2003), as áreas cultivadas sobre o SAG eram muito pequenas, não atingindo 5\%, no entanto percebe-se que a situação atual é diferente, pois hoje as atividades agropecuárias são dominantes.

Além da alta vulnerabilidade à contaminação a que os referidos municípios estão sujeitos, processos de formação de areais (arenização, ou de- 
sertificação antrópica ou induzida) nesses Neosssolos Quartzarênicos, em áreas do sudoeste goiano, inclusive muito próximas às áreas de plantio da cana, foram identificados, como apontam os estudos de Antunes (2006) em Serranópolis, e de Silva (2006) em Mineiros, ambos sinalizando como tendo surgido nos últimos 30 anos. Isto sem falar nos riscos à explotação excessiva do SAG, já que em suas áreas, até o momento, praticamente não existiam culturas anuais irrigadas.

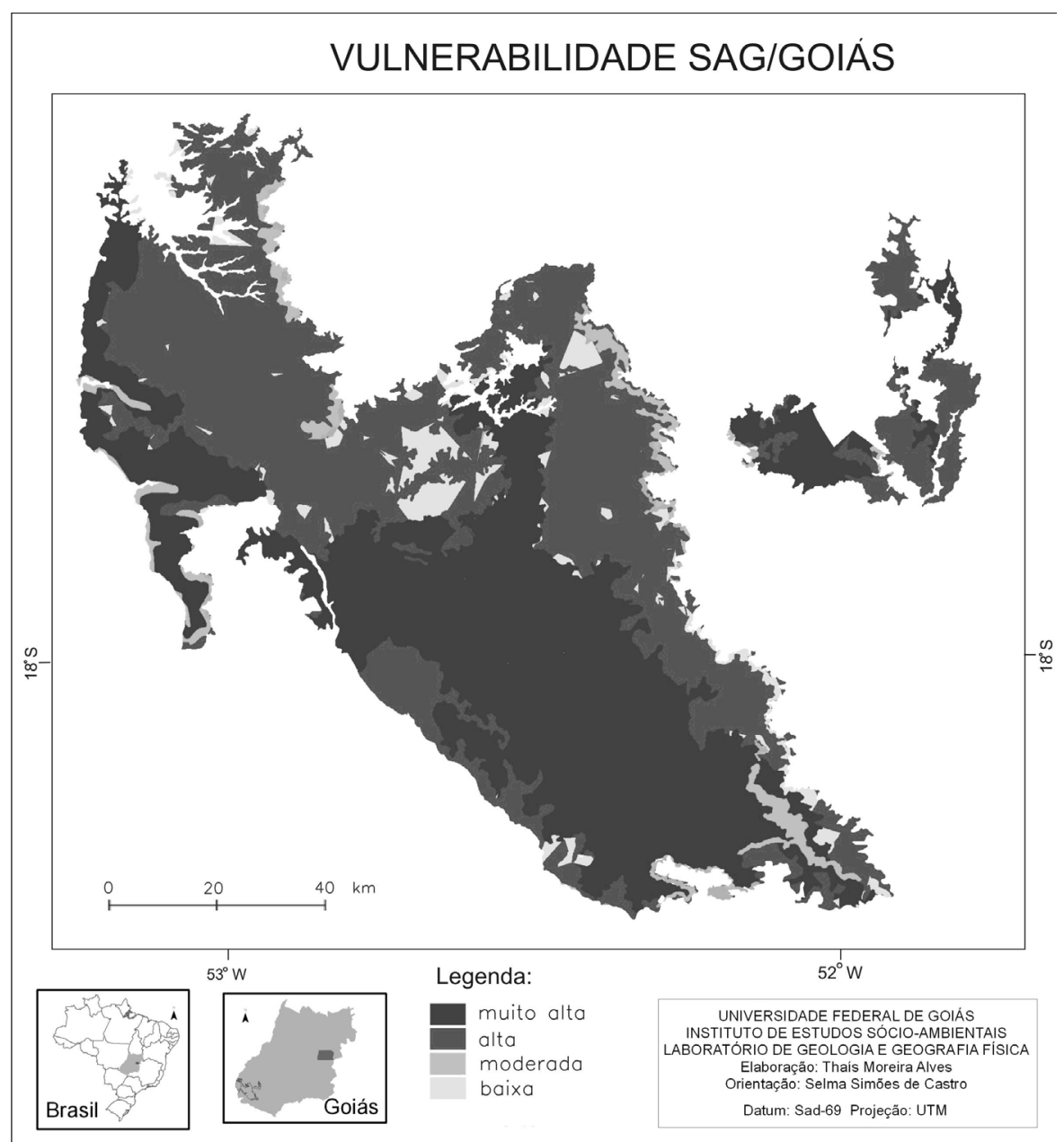

Figura 3 - Mapa de vulnerabilidade à contaminação do SAG no sudoeste goiano. 
Em Serranópolis, o município mais vulnerável da região do SAG, o histórico do uso revela que originalmente a região era coberta por Cerrado típico e Matas de Galeria, tendo sido convertido à cana-deaçúcar na década de 1980, a qual foi desativada após poucos anos, e reconvertido à pastagem extensiva, a qual permaneceu até recentemente, apresentando vários areais e voçorocas de grande porte, além de assoreamento dos canais de drenagem (ANTUNES, 2006). Desde 2005 retorna à cultura da cana em vários setores da região. Em conseqüência de toda a sua fragilidade não são solos adequados à produção agrícola, ainda que essa cultura possa melhorá-los em termos de estrutura, mas restam dúvidas quanto à demanda de água para a agroindústria e a cultura irrigada, bem como ao uso de defensivos e fertirrigação com vinhaça, segundo analisam diversos autores (CASTRO et al, 2007).

Já em Mineiros, apesar dos principais problemas ambientais serem os mesmos, eles estão ligados à monocultura de grãos, sobretudo soja, onde o avanço da cultura sobre os terrenos frágeis, sem aptidão, aliados aos desmatamentos são interpretados como os indutores desses processos de degradação ambiental acelerada (BARBALHO, 2002; MARINHO, 2003; MARINHO, CASTRO \& CAMPOS, 2003; CASTRO, 2005; SILVA \& CASTRO, 2006). Além desses, há o potencial de outros impactos na área, relacionados com a expansão da cana e a instalação e operação de frigorífico e a própria expansão urbana que demanda água para o abastecimento (VAZ, 2008) o que poderá causar impactos no volume e qualidade das águas superficiais e explotação do SAG.

Na região sudoeste, para os demais municípios, destaca-se Jataí, que conforme Carmo, Guimarães e Azevedo (2008) a agricultura intensiva desenvolvida sobre solos argilosos em relevos aplainados já ocupa quase toda sua área, destacando-o como o maior produtor de milho do Brasil, com uma produção total de 546.000 ton (2007), além de ser considerado o maior produtor de grãos do Estado de Goiás (SEPIN, 2008). Esse tipo de agricultura como se sabe, utiliza grande quantidade de insumos agrícolas e água, sobretudo em irrigação.

Quanto à classificação das áreas de risco, pode-se dizer que em correspondência dos solos, relevo e uso, o cenário é potencialmente crítico, dada a grande quantidade de agroquímicos utilizados nas culturas predominantes na região, como o milho, sorgo, soja e cana-de-açúcar (GOMES, FILIZOLA \& SPADOTTO, 2006). 
A análise da Tabela 6 e do mapa de risco à contaminação (Figura 4) permitem constatar que mais de $60 \%$ da área exibem valores de risco elevados (alto a muito alto), e que recentemente estão sendo convertidas, em grande parte, para a agricultura intensiva.

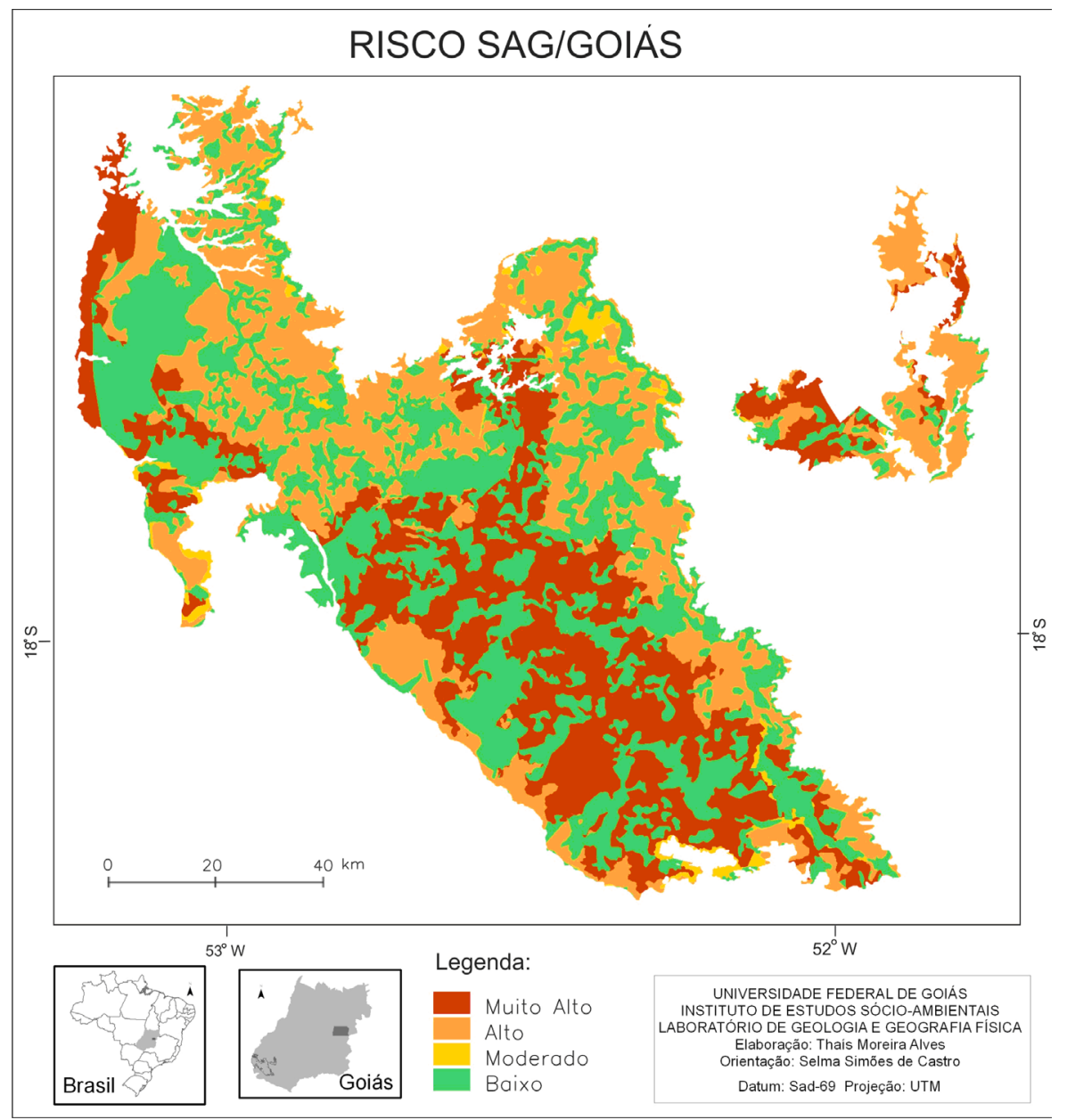

Figura 4 - Mapa de risco à contaminação do SAG no sudoeste goiano. 
Tabela 6 - Cálculo de área de risco à contaminação

\begin{tabular}{lll}
\hline \multirow{2}{*}{ CLASSES DE RISCO } & \multicolumn{2}{l}{ ÁREA } \\
\cline { 2 - 3 } & & Km $^{2}$ \\
\hline Baixo & $3.480,62$ & 37,86 \\
Moderado & 170,0380 & 1,85 \\
Alto & 3013,5232 & 32,78 \\
Muito alto & 2528,5348 & 27,51 \\
TOTAL & $\mathbf{9 . 1 9 2 , 7 5}$ & $\mathbf{1 0 0}$ \\
\hline
\end{tabular}

A análise dos dados da área de ocorrência do SAG em Goiás, relativa aos mapas de declividade, condutividade hidráulica, vulnerabilidade e o de riscos gerados, permite concluir que alto risco, vulnerabilidade muito alta, baixas declividades, condutividade hidráulica muito alta, relacionadas principalmente aos Neossolos Quartzarênicos, são determinantes dos riscos.

Assim, na área de abrangência do SAG pouco mais de $60 \%$ da área estão representados pelas classes de risco muito alto e alto, associadas à declives moderados, de 0 a 6\%, correspondendo a 5.542,058 ha. Apenas 1,8\% possuem risco moderado e quase $38 \%$ apresentam risco baixo.

Em síntese, o município de Mineiros é o mais preocupante, pelo exposto. Jataí e Serranópolis, apesar de apresentarem menores proporções, em termos de área de ocorrência do SAG, onde ele ocorre, predominam as classes alta e muito alta, de risco à contaminação.

Esse risco de contaminação está, sem dúvida, associado às áreas com uso agropecuário intensivo, podendo se estender a áreas que venham a ser desmatadas e convertidas a essa atividade.

Os meses com maior frequência de pluviosidade (período chuvoso) também contribuem com o potencial de lixiviação dos contaminantes, principalmente se o solo estiver desprotegido.

\section{Considerações finais}

A região sudoeste do Estado de Goiás é economicamente importante, por apresentar a maior produção e produtividade agrícola do Estado, e por apresentar terrenos com elevada aptidão agrícola. No entanto, áreas mais frágeis dessa região, indevidamente incorporadas ao sistema produtivo nas últimas três décadas, já apresentam evidências de degradação ambiental acelerada devido a ocorrência de areais, voçorocas, assoreamento e contaminação de solos e canais. Além disso, as próprias áreas com os terrenos de 
maior aptidão agrícola estão sujeitas a contaminação causada pelo uso de agroquímicos associados ao uso intensivo dos solos para a produção agrícola, como mostrou este trabalho.

Nesse sentido, a avaliação da vulnerabilidade natural e do risco dos solos e dos recursos hídricos à contaminação na área de ocorrência do SAG no sudoeste de Goiás, revelaram dados preocupantes devido a áreas extensas apresentarem predominância de classes elevadas de risco que abrangem mais de 60\% da área total e mais de $90 \%$ da sua área de recarga. Por um lado derivados das próprias características do meio físico, marcado pela presença dominante de relevos suaves, solos altamente permeáveis, sobretudo os arenosos, como os Neossolos Quartzarênicos derivados dos arenitos que alojam o próprio aqüífero (borda de bacia sedimentar). Por outro lado, o uso do solo com manejo intensivo de culturas (sobretudo grãos) que exigem grande quantidade de agroquímicos. Some-se a isso a pastagem extensiva, nem sempre com manejo adequado. Destacam-se os municípios de Mineiros, Serranópolis e Jataí como os mais preocupantes, os dois primeiros pela presença dominante dos solos arenosos relatados, o terceiro pelo uso intensivo de agroquímicos.

Espera-se que os resultados apresentados possam contribuir para o prosseguimento de estudos mais específicos do SAG/GO, já que esse sistema, especificamente em Goiás, ainda carece de pesquisa em escala de detalhe quanto à explotação e qualidade. Espera-se também que o trabalho possa orientar o gerenciamento do uso e ocupação das terras e dos recursos hídricos, especialmente subterrâneos, da área em questão. Medidas preventivas, principalmente, no que se refere à contaminação das áreas mais vulneráveis, são fundamentais.

Para que esses dados tenham mais eficácia, sugere-se estudos a respeito das características hidroestratigráficas do Sistema Aqüífero Guarani, devido a sua acentuada compartimentação. Como se trata de um sistema de unidades heterogêneas, esse sistema pode conter, pouca, muita, ou nenhuma água, em suas diferentes regiões.

\section{Referências}

ALMEIDA, R. de C.A. Questão hídrica e a construção de um planejamento urbano sustentável e partícipe: o caso da cidade de São Paulo. In: MARTINS, R.C.; VALENCIO, N.F.L.S. (Org.). Uso e gestão dos recursos hídricos no Brasil: desafios teóricos e político-institucionais. São Paulo: RIMA, 2003. 2 v. 
ANA (AGÊNCIA NACIONAL DE ÁGUAS). Banco de dados hidroweb. Brasília, 2003. Disponível em: <http://www.ana.gov.br>. Acesso em 28 de fev. 2008.

ANTUNES, E. C. Recuperação de áreas degradadas por meio de recomposição vegetal em solos arenosos no sudoeste goiano. Tese de Doutorado - Doutorado em Ciências Ambientais, Universidade Federal de Goiás, Goiânia, 2006.

BARBALHO, M.G. Morfopedologia aplicada ao diagnóstico e diretrizes para o controle dos processos erosivos lineares na alta bacia do rio Araguaia (GO/MT). Dissertação - Instituto de Estudos Sócio-Ambientais, Universidade Federal de Goiás, Goiânia, 2002.

BARBALHO, M.G.; CAMPOS, A.B.de. Vulnerabilidade natural das terras do estado de Goiás a contaminação das águas superficiais e subsuperficiais por vinhaça utilizados na fertirrigação da cultura de cana-de-açúcar. 2008. no prelo.

BERBERT, C.O. O desafio das águas. In: MARTINS, R.C.; VALENCIO, N.F.L.S. (Org.). Uso e gestão dos recursos hídricos no Brasil: desafios teóricos e político-institucionais. São Paulo: RIMA, 2003. $2 \mathrm{v}$.

CARMO, R.L. do.; GUIMARÃES, E.; AZEVEDO, A.M.M. de. Agroindústria, população e ambiente no sudoeste de Goiás. XIII Encontro da Associação Brasileira de Estudos Populacionais, Ouro Preto, Minas Gerais. 2002. Disponível em: <http://www.abep.nepo.unicamp.br/docs/ anais/pdf/2002/GT_MA_ST13_Carmo_texto.pdf> Acesso em: 15 de jun. 2008.

CASTRO, S. S. de. Erosão hídrica na alta bacia do rio Araguaia: distribuição, condicionantes, origem e dinâmica atual. Revista do Departamento de Geografia, São Paulo, n. 17, p. 38-60, 2005.

EMBRAPA. Centro Nacional de Pesquisa do Solo. Disponível em: < http://www.cnpma.embrapa.br/projetos/index.php3?sec=guara $>$ Acesso em: 13 de fev. 2008.

GEOGOIÁS (2003). Maurício Galinkin, ed. Goiânia: Agência Ambiental de Goiás: Fundação CEBRAC: PNUMA: Semarh. 272p.

GOIÁS (Estado). Secretaria de Indústria e Comércio. Hidrogeologia do Estado de Goiás. Goiânia: Superintendência de Geologia e Mineração, 2006. (Geologia e Mineração, n.1).

GOMES, M.A.F.: SPADOTTO, C.A.: PESSOA, M.C.P.Y. Avaliação da vulnerabilidade natural do solo em áreas agrícolas: subsídio à avaliação do risco de contaminação do lençol freático por agroquímicos. Pesticidas: R. Ecotoxicol. e Meio Ambiente, Curitiba, v. 12, jan./ dez. 2002.

GOMES, M.A.F.; FILIZOLA, H.F.; SPADOTTO, C.A. Classificação das áreas de recarga do sistema aqüífero guarani no Brasil em domínios Pedomorfoagroclimáticos - subsídios aos estudos de avaliação de risco de contaminação das águas subterrâneas. Revista do Departamento de Geografia, 18 (2006) 67-74.

LIMA, W.P. de. Ciclo hidrológico e balanço hídrico. In: LIMA, W.P de. Manejo de bacias hidrográficas. Disponível em: <http://www.esalq.usp.br/departamentos/lcf/lab/lhf/arquivos/CAPITULO\%201.pdf> Acesso em: 1 de mar. 2008.

MARINHO, G. V. Caracterização físico-hídrica e suscetibilidade erosiva linear na sub-bacia do córrego queixada, na alta bacia do rio Araguaia-GO. Mestrado em Geografia - Instituto de Estudos Sócio-Ambientais. Universidade Federal de Goiás. Goiânia. 2003. 
MARINHO, G. V.; CASTRO, S. S. ; CAMPOS, A. B de. Hydrology and gully processes in the upper araguaia river basin, central Brazil. Zeitschrift für Geomorphologie. Supplementband, v. 145 , p. $119-145,2006$

SEPIN. Superintendência de Estatística, Pesquisa e Informação. Perfil socioeconômico. Disponível em: <http://www.seplan.go.gov.br/sepin/viewnot.asp?id_cad=1070\&id_not $=4>$ Acesso em: 12 de jul. 2008.

SILVA, R.A.A ; CASTRO, S.S de . Relação entre relevo e arenização no setor sul da alta bacia do rio Araguaia (GO-MT-MS). In: Regional Conferende on Geomorpholy/ VI Simpósio Nacional de Geomorfologia, 2006, Goiânia. Anais/ Actes - VI SINAGEO/ RCG. Goiânia : CEGRAF-UFG, 2006. v. 1. p. 129-129.

Thaís Moreira Alves - Mestranda do Programa de Pós-Graduação do Instituto de Estudos Sócio-Ambientais da UFG.

Selma Simões de Castro - Professora titular do Instituto de Estudos Sócio-Ambientais da UFG.

Recebido para publicação em Março de 2009

Aceito para publicação em Junho de 2009 